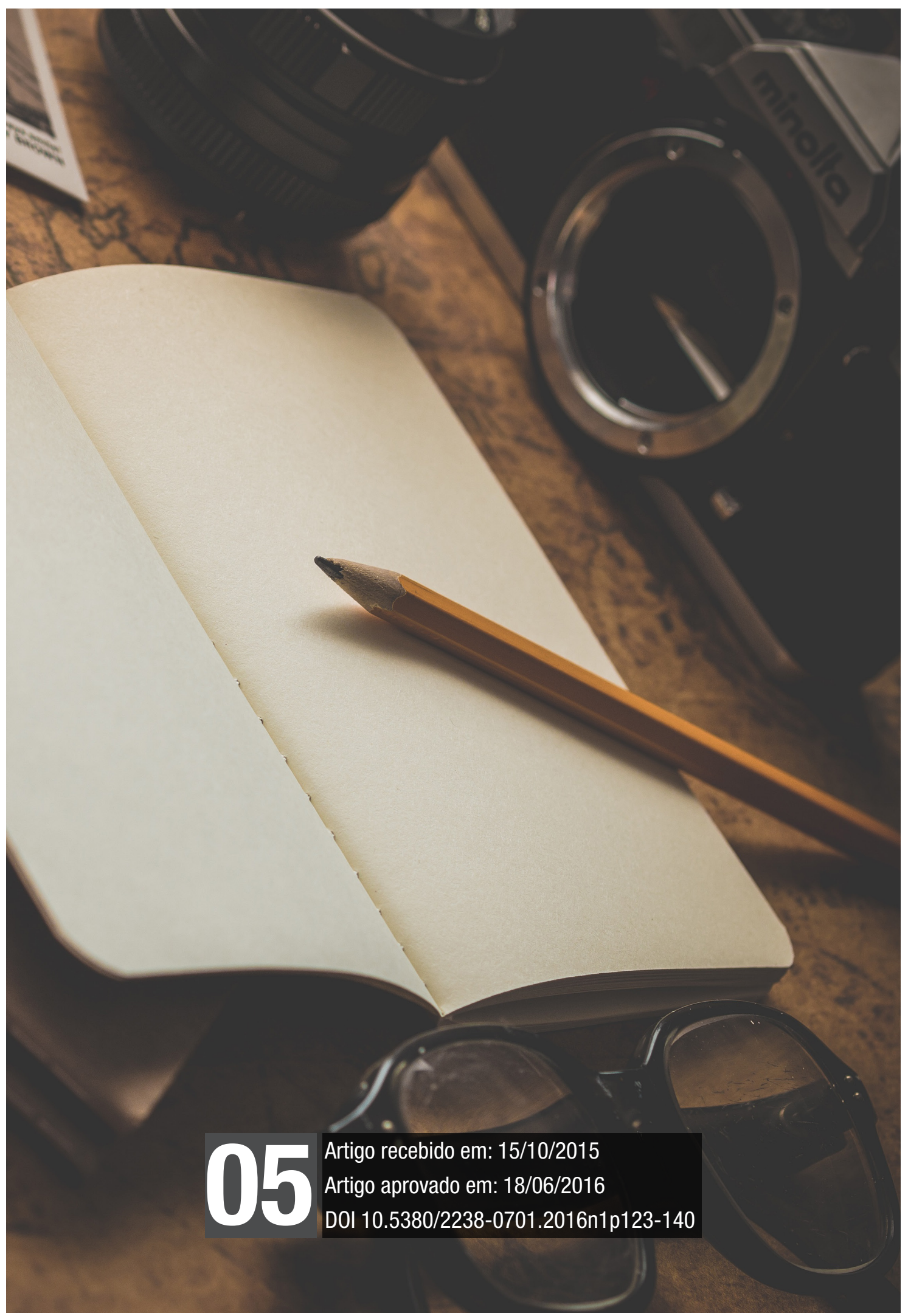


Diários. Narrativas biográficas. Narrativas contemporâneas.

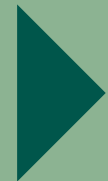




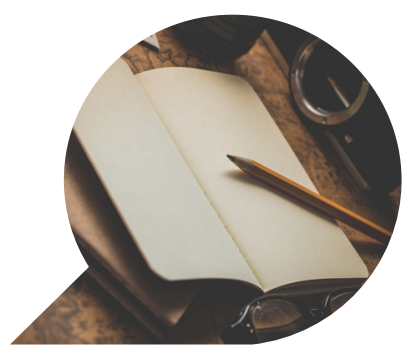

\title{
Narrativas biográficas: \\ o olhar testemunhal dos diários e sua relação com a prática da cidadania
}

\author{
Biographical narratives: the witness look at the journals and \\ its relation to the practice of citizenship
}

\begin{abstract}
Narraciones biográficas: la mirada testigo en el diario y su relación con la práctica de la ciudadanía
\end{abstract}

\section{MONICA MARTINEZ}

Resumo: A partir do levantamento dos trabalhos apresentados na Sociedade Brasileira de Estudos Interdisciplinares da Comunicação (Intercom) sobre o tema diários, esse estudo tem como objetivo articular uma possível relação entre a prática da cidadania comunicacional da pesquisa sobre os diários íntimos, seja em suas apresentações tradicionais, comumente em suportes impressos, ou em suas apresentações mais recentes, disponibilizadas em ambientes digitais. Propõe-se que esses registros, uma vez disseminados, tenham um poder de influência cidadã, logo abarcando do individual ao comunitário, bem como o humanitário, dependendo de uma miría-

\footnotetext{
* Doutora em Ciências da Comunicação pela ECA-USP, com pós-doutorado em Narrativas Digitais pela UMESP e estágio pós-doutoral pelo Departamento de Rádio, TV e Cinema da Universidade do Texas (EUA). Colíder do Grupo de Pesquisa em Narrativas Midiáticas (NAMI) - UNISO/CNPq. Diretora científica da Associação Brasileira de Pesquisadores em Jornalismo (SBPJor), onde é colíder da Rede de Pesquisas em Narrativas Midiáticas Contemporâneas (RENAMI). Docente do Programa de Pós-Graduação em Comunicação e Cultura da Universidade de Sorocaba (Uniso), em São Paulo.
} 
de de possibilidades que contemplem desde a visão de mundo ampla do(a) autor(a) às necessidades de ação e reflexão de grupos sociais num dado momento sócio histórico.

Palavras-chave: Diários; Narrativas biográficas; Narrativas contemporâneas.

Abstract: Based upon the collected papers presented at the Brazilian Society of Interdisciplinary Studies of Communication (Intercom) on the daily theme, this study aims to articulate a possible relationship between the practice of citizenship and the research on the diaries, whether in their traditional presentations, commonly in printed media, or in its most recent presentations, available in digital environments. It is proposed that these records have a power of citizen influence encompassing the individual to community and humanitarian, depending on a myriad of possibilities that includes the wide world view of man author and female author to needs for action and reflection of social groups in a given socio historical moment.

Keywords: Biographical narratives; Contemporary narratives; journals.

Resumen: A partir de la encuesta de los trabajos presentados en la Sociedad Brasileña de Estudios Interdisciplinarios de la Comunicación (Intercom) sobre el tema diario, este estudio tiene como objetivo articular una posible relación entre la práctica de la ciudadanía y la investigación en los diarios, ya sea en sus presentaciones tradicionales, comúnmente en los medios de comunicación impresos, o en sus presentaciones más recientes, disponibles en ambientes digitales. Se propone que estos registros tienen un poder de influencia ciudadana abarca al individuo a la comunidad y humanitaria, en función de un gran número de posibilidades que incluye la amplia visión del mundo de autores hombres y mujeres la necesidad de la acción y la reflexión de los grupos sociales en un momento socio histórico determinado.

Palabras clave: Diario; Narrativas contemporáneas; Relatos biográficos. 


\section{Introdução}

Ao lançarmos, por exemplo, a palavra-chave "diários" no Portcom, o portal de banco de dados da Sociedade Brasileira de Estudos Interdisciplinares da Comunicação (Intercom), nota-se a emersão de 36 registros. Destes, excluindo-se os trabalhos que versam sobre diários relacionados à mídia impressa, isto é, jornais e também os trabalhos apresentados por jovens pesquisadores na seção Intercom Júnior, o resultado apontado é reduzido a 12 trabalhos, isso se tendo em vista o período de 2002 (quando surge o primeiro registro do termo) a 2014.

Todavia, não é objetivo deste artigo realizarmos uma análise de conteúdo (BARDIN, 2011) aprofundada sobre o corpus acima demostrado, dada a possiblidade de sua pesquisa num estudo futuro. Contudo, para fins de compreensão desse universo, pretendemos realizar no presente trabalho o levantamento de títulos, autores e de instituições, entre elas universidades federais, estaduais e privadas. Para tanto, distribuímos a produção científica então levantada em três categorias relacionadas às mídias a partir das quais o trabalho foi concebido: a impressa, a eletrônica e a digital. Em linhas gerais, são elas:

1. Mídia impressa: reflexões sobre livros impressos que reproduzem diários, estes enquanto a prática de um indivíduo registrar com certa periodicidade seu cotidiano em suportes tradicionais, como cadernos;

2. Mídia eletrônica: trabalhos sobre produtos midiáticos televisivos e, na maioria dos casos, cinematográficos.

3. Mídia digital: estudos sobre os novos formatos de registro de diários surgidos com o desenvolvimento da Internet, como os diários pessoais registrados em blogs, fotoblogs e outros. 
Tabela 1: Pensamento comunicacional sobre diários na Intercom (2002-2014)

\begin{tabular}{|c|c|c|c|c|}
\hline $\begin{array}{l}\mathrm{N} / \\
\text { Ano }\end{array}$ & Título & Autoria & NP/GT & $\begin{array}{c}\text { Mídia } \\
\text { analisada }\end{array}$ \\
\hline $\begin{array}{c}1 \\
2014\end{array}$ & $\begin{array}{c}\text { O roteiro aberto como } \\
\text { caminho para as instruções } \\
\text { documentarizantes em Diários } \\
\text { de Motocicleta }\end{array}$ & $\begin{array}{l}\text { Sancler Ebert } \\
\text { (UFSCAR) }\end{array}$ & Cinema & Eletrônica \\
\hline $\begin{array}{c}2 \\
2013\end{array}$ & $\begin{array}{l}\text { O eu no contemporâneo: } \\
\text { o privado e o público } \\
\text { transformados em espaço } \\
\text { comum através dos diários } \\
\text { íntimos }\end{array}$ & $\begin{array}{l}\text { Pâmela } \\
\text { Rochelle } \\
\text { Rochane Dias } \\
\text { de Oliveira } \\
\text { (UERN) }\end{array}$ & Jornalismo & Digital \\
\hline $\begin{array}{c}3 \\
2012\end{array}$ & $\begin{array}{c}\text { Entre diários e mapas: modos } \\
\text { de apreensão das práticas } \\
\text { juvenis }\end{array}$ & $\begin{array}{l}\text { Daniela } \\
\text { Abreu Matos } \\
\text { (UFRB) }\end{array}$ & $\begin{array}{l}\text { Comunicação } \\
\text { e Culturas } \\
\text { Urbanas }\end{array}$ & Digital \\
\hline $\begin{array}{c}4 \\
2007\end{array}$ & $\begin{array}{l}\text { Entre a utopia e o ceticismo: } \\
\text { as potencialidades dos diários } \\
\text { virtuais no mercado de } \\
\text { comunicação nacional }\end{array}$ & $\begin{array}{c}\text { Mariana } \\
\text { Della Dea } \\
\text { Tavernari } \\
\text { (ECA/USP) } \\
\end{array}$ & $\begin{array}{l}\text { Tecnologias da } \\
\text { Informação e da } \\
\text { Comunicação }\end{array}$ & Digital \\
\hline $\begin{array}{c}5 \\
2006\end{array}$ & $\begin{array}{l}\text { Viajando com os Diários } \\
\text { de Motocicleta: análise das } \\
\text { possibilidades turísticas do } \\
\text { filme Diários de Motocicleta }\end{array}$ & $\begin{array}{l}\text { Cláudio Luis } \\
\text { de Camargo } \\
\text { Penteado } \\
\text { (UniABC) }\end{array}$ & $\begin{array}{l}\text { Comunicação, } \\
\text { Turismo e } \\
\text { Hospitalidade }\end{array}$ & Eletrônica \\
\hline $\begin{array}{c}6 \\
2005 \\
\end{array}$ & $\begin{array}{c}\text { Dez anos depois do boom dos } \\
\text { diários digitais }\end{array}$ & $\begin{array}{l}\text { C. I. Quadros } \\
\text { (UTP) }\end{array}$ & Jornalismo & Digital \\
\hline $\begin{array}{c}7 \\
2005 \\
\end{array}$ & $\begin{array}{c}\text { A edição de diários íntimos e } \\
\text { o caso de Anne Frank }\end{array}$ & $\begin{array}{l}\text { A. S. Moroni } \\
\text { (UAB) }\end{array}$ & $\begin{array}{l}\text { Produção } \\
\text { editorial }\end{array}$ & Impressa \\
\hline $\begin{array}{c}8 \\
2005 \\
\end{array}$ & $\begin{array}{l}\text { Diários virtuais/visuais: uma } \\
\text { análise da fotografia nos } \\
\text { fotoblogs }\end{array}$ & $\begin{array}{l}\text { A. Teles } \\
\text { (FURB) }\end{array}$ & & Digital \\
\hline $\begin{array}{c}9 \\
2004\end{array}$ & $\begin{array}{l}\text { A condição do sujeito como } \\
\text { autor-produtor nos diários } \\
\text { online - examinando alguns } \\
\text { aspectos }\end{array}$ & $\begin{array}{l}\text { Gustavo } \\
\text { D. Fischer } \\
\text { (Unisinos) }\end{array}$ & $\begin{array}{l}\text { Tecnologias da } \\
\text { Informação e da } \\
\text { Comunicação }\end{array}$ & Digital \\
\hline $\begin{array}{c}10 \\
2003\end{array}$ & $\begin{array}{l}\text { Relações sujeito-tempo } \\
\text { nos diários online, o } \\
\text { "armazenamento de agoras" }\end{array}$ & $\begin{array}{l}\text { Gustavo } \\
\text { D. Fischer } \\
\text { (Unisinos) }\end{array}$ & $\begin{array}{l}\text { Tecnologias da } \\
\text { Informação e da } \\
\text { Comunicação }\end{array}$ & Digital \\
\hline $\begin{array}{r}11 \\
2002 \\
\end{array}$ & $\begin{array}{l}\text { Entre o texto, o autor e } \\
\text { o leitor: uma questão de } \\
\text { contrato } \\
\end{array}$ & $\begin{array}{l}\text { V. Maia } \\
\text { (FAESA) }\end{array}$ & Jornalismo & Impressa \\
\hline $\begin{array}{c}12 \\
2002\end{array}$ & $\begin{array}{l}\text { A arte da vida: diários pessoais } \\
\text { e webcams na Internet }\end{array}$ & $\begin{array}{l}\text { André Lemos } \\
\text { (UFBA) }\end{array}$ & $\begin{array}{l}\text { Tecnologias da } \\
\text { Informação e da } \\
\text { Comunicação }\end{array}$ & Digital \\
\hline
\end{tabular}


A respeito da distribuição de estudos por mídias, esta nos permite observar a preocupação dos pesquisadores em investigar a produção visível nos novos formatos e suportes, uma vez que 8 dos 12 trabalhos (66\%) versa sobre o universo digital. Empatadas, seguem as mídias eletrônicas (2 trabalhos, cerca de 17\%) e impressas (2 trabalhos, cerca de 17\%). Cumpre elencarmos que esses estudos contemplam diários famosos, como o de Anne Frank (1929-1945) e o de Ernesto Che Guevara (1928-1967), além do filme de Walter Salles Diários de Motocicleta; obra sobre o diário de Guevara de 2004.

\section{Diários: relatos pessoais e cidadania}

Prosseguindo com nosso estudo, essa seção procura articular uma provável relação entre a prática da cidadania e a pesquisa sobre os diários íntimos, considerando suas apresentações tradicionais, suportes impressos ou eletrônicos, e ainda em suas apresentações mais recentes, disponibilizadas em ambientes digitais.

Do ponto de vista histórico, o registro de diários remonta às culturas do Oriente Médio e Ásia, bem como à Grécia antiga. Contudo, pode-se dizer que foi no Renascimento, com a ênfase humanista no indivíduo, que os diários começam a ter importância como um registro pessoal, opinativo e privado dos acontecimentos. Esse olhar testemunhal, em geral de natureza confidencial e para uso exclusivo do(a) autor(a), é considerado interessante justamente porque seu nível de registro varia de acordo com a própria amplitude com que o(a) autor(a) observa e reflete sobre a realidade na qual está inserido(a). Desse modo, os diários poderiam conter crônicas políticas e econômicas que passariam ao largo dos registros oficiais. É o caso do membro do parlamento britânico Samuel Pepys (1633-1703), que por dez anos registrou sua visão sobre fatos notáveis do período, como o incêndio de Londres de 1666.

Além de fatos políticos, encontra-se igualmente presente nesses registros a crítica social, como, por exemplo, citando o escritor londrino Daniel Defoe (1660-1731), autor de Robinson Crusoe, que publicou, em 1722, A journal of the plague year (O Diário do Ano da Peste). Nessa obra, Defoe descrevia a epidemia de peste bubônica que vitimou, segundo ele, 100 mil pessoas na capital inglesa em 1665 (DEFOE, 2006). No jornalismo, o inglês Charles Dickens (1812-1870), colaborador do jornal Morning Chronicle, em uma viagem à América critica o sistema tabagista e escravagista no livro 
Notas americanas para circulação geral ${ }^{1}$ (American notes for general circulation, 2000), lançado em 1842.

Não obstante, nota-se desde o princípio também a forte relação entre os diários e as narrativas de viagem (MARTINEZ, 2012). O escritor irlandês Jonathan Swift (1667-1745) escreveu Diário para Stella ${ }^{2}$ (Journal to Stella,1710-13). Pioneiro em biografias, o escocês James Boswell (1740-1795) foi um grande escritor de diários, sendo que seu Diário de uma viagem para as Hebrides ${ }^{3}$ (Journal of a Tour to the Hebride,1785) foi o primeiro a ser publicado ainda durante a vida do autor e não como uma obra póstuma como era costume então na época.

Afora abordagens política e viagens, os diários contemplam ainda o cenário artístico e cultural nos quais observamos a inserção do(a) autor(a). Exemplos são os diários de Vaslav Nijinsky (1890-1950), notável bailarino russo (NIJINSKY, 1968), e de Paul Klee (18981918), pintor suíço (KLEE, 1968) cuja obra Angelus novus (1920) foi objeto de reflexão sobre a noção de história pelo filósofo alemão Walter Benjamin (1892-1940). Pontuamos também os cinco volumes de Virgínia Woolf (1882-1941), em cuja nota de 15 de novembro de 1918 a escritora registra num destes diários suas impressões sobre o escritor T.S. Eliot:

Mostrou-nos uns três ou quatro poemas para lhe darmos uma vista de olhos - o fruto de dois anos de trabalho, visto que ele trabalha o dia inteiro num banco e, segundo o seu modo racional de pensar, acha que o trabalho regular faz bem às pessoas de constituição nervosa. Fiquei mais ou menos consciente de um seu sistema, muito intrincado e altamente organizado, de crença poética; devido às suas cautelas, e ao seu cuidado excessivo na escolha da linguagem, não descobrimos muita coisa sobre essa crença. Acho que ele é um adepto das "frases vivas" e acredita que há uma diferença entre estas e as frases mortiças; acha que se deve escrever com um cuidado extremo, respeitar sintaxe e gramática; e, assim, fazer esta poesia nova florir dos estames da mais antiga poesia. [...] (WOOLF, 1989, p. 132).

Sobremodo, o conteúdo que nos parece mais fascinante acerca dos diários são os registros do cotidiano, da vida diária, as observações de caráter eminentemente pessoais que, graças a tais, escritos,

\footnotetext{
${ }^{1}$ Tradução nossa.

${ }^{2}$ Tradução nossa.

${ }^{3}$ Tradução nossa.
} 
chegam preservados aos tempos atuais com a mesma riqueza dos afrescos de Pompeia. Talvez seja por esse motivo que, em pleno século XXI, os blogs e demais ambientes sociais continuam uma forma importante de narrativa não ficcional.

\section{Diários como mensagens em garrafas no oceano midiático}

Por meio do uso excertos, faremos nesse momento uma tentativa de exemplificação da influência cidadã nesse gênero narrativo. A resvista piauí tem tradição na publicação de diários. Na edição de outubro de 2015, a revista publicou um trecho do diário de Verônica, Nina e Ana, que oficializaram a primeira relação estável entre três mulheres no Brasil. Neste diário, escrito a seis mãos, as autoras debatem questões pessoais, como a divisão de tarefas e a acomodação de três pessoas numa cama de casal, mas também registram como modulam conscientemente a exposição da relação do trio, sobretudo no âmbito profissional, uma vez que o paradigma de relacionamentos estáveis baseado entre pares heterossexuais está sendo gradualmente rompido no Ocidente, mas que ainda enfrenta preconceito em algumas esferas. Os trechos abaixo são escritos respectivamente por Nina, 34 anos, gerente administrativa, e por Ana, 32, dentista:

Tempo chuvoso, um daqueles dias que dá vontade de ficar em casa. Peguei o carro e saí para o trabalho. Muito trânsito, por causa da chuva. Cheguei atrasada, lógico. Sou gerente administrativa e de pessoal numa empresa de serviços. Abaixo do dono, quem comanda sou eu. Trabalho só com homens, ninguém sabe da minha vida. Não sabem da minha sexualidade e muito menos que sou casada com duas mulheres. Fico imaginando o que aconteceria se meu chefe descobrisse: ele é machista ao extremo, além de homofóbico. No trabalho sou obrigada a viver uma vida dupla. [...] (VERÔNICA; NINA; ANA, 2015, p. 33).

Lá no trabalho as pessoas sabem da minha homossexualidade, sabem que sou casada - mas acham que sou casada apenas com a Verônica. Sempre me respeitaram, nunca tive problemas de convivência. [...] (VERÔNICA; NINA; ANA, 2015, p. 36-37).

Esse retrato do dia a dia, dos usos e costumes, de certas famílias e grupos sociais, estaria presente também no livro Minha vida de menina, no qual a brasileira Helena Morley (1880-1970) registra 
o cotidiano mineiro do final do século XIX pela ótica de uma adolescente (MORLEY, 1998). Helena era o pseudônimo de Alice Dayrell Caldeira Brant, e o diário cobre os anos de 1893-1895:

Hoje, quando me levantei, já encontrei mamãe com tudo pronto para irmos para o rio lavar a roupa amontoada de mais de uma semana. [...] Fomos todos com tia Agostinha, Naninha, Glorinha e a criada delas Benvinda; nós para lavarmos as roupas e meus irmãos com mais obrigações ainda, pois tinham de buscar lenha, fazer vassoura para a casa, pescar e armar as arapucas na esperança de alguma pomba. Íamos na maior alegria e no meio do caminho mamãe se separou de nós para levar o almoço de meu pai, na lavadeira. Ela mesma é que gosta de ir para ficar perto de meu pai. Chegados ao rio nós ficamos na praia e meus irmãos entraram no mato. A velha Luzia arrumou as pedras, fez a trempe, colocou o caldeirão de feijão e acendeu o fogo. Eu e Luisinha4 enchemos a bacia de roupa e nos pusemos a ensaboar. Minha tia e as primas fizeram o mesmo e Benvinda foi procurar lenha e ajudar a fazer o almoço. Ensaboamos as roupas e estendemos nas pedras para corar, tudo com pressa pois sempre temos muitos planos e já estávamos na hora do almoço. Sentamo-nos na praia com nossos pratos feitos como para trabalhador; feijão de tropeiro com farinha, torresmos, ovos fritos e arroz; sobremesa, banana e queijo. Delicioso!

[...] Minhas tias contam histórias do casamento delas. As únicas que casaram por seu gosto, conhecendo os maridos, foram mamãe e tia Aurélia, porque casaram depois da morte de vovô. Para as outras vovô escolhia o marido que ele queria. Só Dindinha escapou de casar com um fazendeiro burro, por milagre. Elas ficavam espiando pelo buraco da fechadura e diziam uma à outra: "Eu penso que aquele assim assim é o meu”. [...] (MORLEY, 1998, p. 328-329).

O trecho acima, como vários outros do diário apresentado, permite uma volta a um tempo em que as cidades não dispunham de energia elétrica nem dos equipamentos eletroeletrônicos que se difundiriam somente mais de meio século depois. Registra igualmente os costumes relacionados ao matrimônio no contexto de uma sociedade patriarcal. Como afirma a historiadora brasileira Mary Del Priore:

Constituindo um contrato civil antes de se tornar sacramento - o que só ocorre na Europa em meados do século XII - o casamento é uma instituição básica para a transmissão do patrimônio, sendo

\footnotetext{
${ }^{4}$ A irmã de Helena, nota da autora.
} 
sua origem fruto de acordos familiares e não da escolha pessoal do cônjuge. A garantia de igualdade era fundamental para impedir a dispersão de fortunas acumuladas. A importância dessa questão se reflete no século XVIII, quando na reforma da legislação de Pombal em Portugal se reforça a autoridade paterna para impedir os casamentos desiguais. [...] (DEL PRIORE, 2006, p. 27).

Nessa época, apenas membros das classes subalternas conseguiam escolher seus cônjuges de forma mais espontânea. Tal como os camponeses europeus, os pobres da colônia não tinham interesses político-econômicos para preservar e, por isso, podiam deixar aflorar seus sentimentos. [...] (DEL PRIORE, 2006, p. 26).

Como demostrado no livro de Morley, há outras obras que registram de forma parcial ou integral o cotidiano de certos indivíduos ou grupos cuja leitura permitiria uma melhor compreensão sócio histórica de um determinado período. Em exemplo a tanto, cumpre citarmos o livro De moto pela América do Sul, escrito aos 23 anos pelo então estudante de medicina Ernesto Che Guevara (1928-1967), obra em que, ao conhecer a América Latina, o então estudante tem os olhos abertos para as agruras sociais enfrentadas pelos habitantes da região. O mesmo livro seria base para o filme Diários de Motocicleta, realizado em 2004 pelo diretor brasileiro Walter Salles. Estariam nessa categoria também obras como o Diário de Guadalcanal (Richard Tregasakis, Ed. Objetiva), escrito em 1942 quando o jornalista tinha 23 anos, e Diário de um detento (Jocenir Prado, Labortexto, 2001), com prefácio de Dráuzio Varella.

Pontuamos também a existência de registros que ainda possibilitariam ao leitor refletir e conscientizar-se sobre eventos que afetam de forma direta ou indireta a humanidade. Estariam nessa categoria obras como O diário de Zlata Filipovic (Companhia das Letras, 1994), O diário de Lena: a história real de uma adolescente durante a Segunda Guerra (Lena Mukhina, Globo Livros, 2015) e Diários de Berlim 1940-1945 (Marie Vassiltchikov, Boi Tempo Editorial, 2015). Vale assinalar que, pela data de publicação desses dois últimos livros, notamos um interesse das editoras pela publicação de diários ainda hoje.

Continuando com a análise, sobre os diários de crianças e de adolescentes, Zlata Filipovic mostra que estes podem ser ferramentas poderosas de conscientização. O registro dos acontecimentos recortados pelo olhar infanto-juvenil também foi registrado pela autora 
numa obra coorganizada posteriormente, Vozes roubadas (2008), que reúne 14 outros diários infanto-juvenis que abarcam da Primeira Guerra Mundial à invasão do Iraque em 2003 (FILIPOVIC; CHALLANGER, 2008). Em 1992, a autora de O diário de Zlata Filipovic tinha 11 anos e vivia sua vida de menina, em Saravejo, quando eclode a guerra da Bósnia e sua cidade, Sarajevo, ficou sitiada por forças sérvias durante quase quatro anos.

Descoberto em 1990, O diário de Lena foi escrito pela então adolescente Lena Mukhina, na época com 16 anos. A obra narra o cerco de 872 dias de Leningrado, em 1941, durante a invasão nazista à Rússia, quando mais de 700 mil civis pereceram. O registro de 2 de janeiro de 1942 evidencia o cotidiano marcado pelo racionamento de víveres, tais quais a energia: "Se houvesse luz, poderíamos ainda, de um jeito ou outro, viver: ler, costurar etc. Mas o que fazer sem luz? Somos obrigadas, querendo ou não, a nos deitar às $6 \mathrm{~h}$ da tarde." (MUKHINA, 2015, p. 139), a água “é preciso descer ao térreo, no andar da administração do prédio" (MUKHINA, 2015, p. 139), e ainda a comunicação "O rádio também quase nunca funciona. Às vezes ouve-se uma voz que começa a falar ou cantar e depois se cala novamente" (MUKHINA, 2015, p. 139). Nesse contexto de privação, até a morte pode ser uma boa companheira:

Agora que Aka não está mais conosco, a vida ficará menos cara para nós duas. Vamos dividir tudo por dois e não mais por três, como antes. É uma enorme diferença. Mamãe tinha duas pessoas para dependentes de seu salário, agora tem uma só. Até então seiscentos rublos por mês mal bastavam, agora, com tudo o que aprendemos, quatrocentos serão amplamente suficientes. De forma que mesmo a morte de Aka, de quem gostávamos tanto, teve seu lado positivo. Como diz o provérbio russo: “Toda desgraça traz algo de bom”. [...] (MUKHINA, 2015, p. 139-140).

A Segunda Guerra Mundial é uma ferida ainda vívida e aberta graças aos registros dos diários. Em 2012, a professora da PUC-SP, Noemi Jaffe, lançou $O$ que os cegos estão sonhando, obra que contêm os registros de sua mãe, Lili, sobrevivente de Auschwitz, campo de concentração localizado na Polônia ocupada (JAFFE, 2012).

Também nascida na Rússia, em São Petesburgo, Marie Vassiltchikov (1917-1978) era filha do príncipe Illarion e da princesa Lydia Vassiltchikov. Em 1919, a família deixou a terra natal com destino à 
Alemanha, posteriormente França e Lituânia. Em 1940, ela e uma irmã foram para Berlim, onde trabalharam no Serviço de Rádio e, mais tarde, no Departamento do Ministério do Exterior. Fervorosa antinazista, Marie acompanhou de perto a Conspiração de 20 de Julho, fracassada tentativa do conde Von Stauffenberg para matar Adolf Hittler, segundo observamos no fragmento abaixo:

Quinta-feira, 20 de julho/ [...] O conde Claus Sckenk von Stauffenberg, um coronel do Estado-Maior, colocara uma bomba aos pés de Hitler durante uma conferência no QG de Rastenburg, na Prússia Oriental (hoje território polonês). Ela explodira, e Hitler estava morto. Stauffenberg esperara do lado de fora pela explosão e, vendo Hitler carregado numa maca e coberto de sangue, correra para o seu carro, que ficara escondido em algum lugar, e com seu ajudante de campo, Werner von Haefen, fora para o campo de aviação local e voara de volta para Berlim. Na comoção geral, ninguém notara sua fuga. [...] (VASSILTCHIKOV, 2015, p. 304).

Se torna oportuno salientar que, ao prefaciar a obra, George, o irmão da autora, pondera que a esta "escrevia seu diário de modo compulsivo. Diariamente ela datilografava um sumário dos acontecimentos. Apenas as narrativas mais longas, como a dos bombardeios de Berlim em novembro de 1943, foram escritas 'ex post facto'. Observemos o trecho a seguir:

Ela acreditava firmemente que qualquer valor que seu diário tivesse se deveria ao fato de ser completamente espontâneo, honesto e escrito sem reservas, uma vez que originalmente não se destinava à publicação. Seus testemunhos oculares, suas reações e emoções no calor da hora falavam por si mesmos: essa era sua impressão. Tudo perderia muito de seu interesse se algo fosse adulterado por um juízo posterior aos eventos, sem falar na possibilidade de (auto) censura para preservá-la de constrangimentos e sentimentos de outras pessoas. Essa versão do diário - a terceira e definitiva - ficou pronta algumas semanas antes de sua morte. [...] (VASSILTCHIKOV, 2015, p. C8-C9).

De todos os diários, talvez nenhum tenha tido mais repercussão do que o de uma garotinha que começou o seu aos 13 anos, em 1942, e o escreveu por dois anos enquanto esteve abrigada, com a família, por amigos na Holanda ocupada: a alemã de origem judaica Anne Frank (1929-1945). Publicado em 1947, a obra teve recentemente nova edi- 
ção lançada, agora sem as alterações paternas. Após o fracassado atentado do conde Von Stauffenberg, ela escreve, em 21 de julho:

Agora estou ficando realmente esperançosa. Finalmente as coisas vão bem, muito bem mesmo! Houve um atentado contra a vida de Hitler e desta vez não foi ato de judeus comunistas ou capitalistas ingleses; foi um orgulhoso general alemão e - o que é mais - ele é conde e bastante jovem. A Divina Providência salvou a vida do Führer e infelizmente ele conseguiu escapar com apenas alguns arranhões e queimaduras. Alguns generais e oficiais que estavam com ele ficaram feridos ou morreram. O principal culpado foi fuzilado. De qualquer modo, essa é a prova de que existem muitos oficiais e generais que estão fartos da guerra e gostariam de ver Hitler despencar num abismo sem fundo. [...] (FRANK, 1988, p. 222).

Trata-se da penúltima anotação de Anne: a última seria escrita em $1^{\circ}$ de agosto de 1944. Após uma denúncia, em 4 de agosto, a família holandesa que abrigava Anne e seus familiares foi obrigada pela Polícia de Segurança Alemã a revelar a entrada do esconderijo, e uma vez detidos, a família Frank foi enviada a Auschwitz, consequentemente.

\section{Os diários dos pensadores do campo da comunicação}

Por fim, o presente artigo não estaria completo sem mencionar os diários feitos por pensadores da Comunicação. Como exemplo, destacamos a trilogia escrita pelo francês Edgar Morin, que registra seu dia a dia durante os anos de 1994, 1995 e 1996, lançada em 2012 pela Edições Sesc SP. No prefácio do segundo volume, Chorar, amar, rir, compreender, Morin sintetiza o poder dos diários:

Meu diário me revela que, no decorrer do dia, salto (salto quântico) de um plano a outro: de um microacontecimento pessoal que concentra toda a minha atenção, me diverte ou me aborrece, à terrível situação na Bósnia ou em Ruanda; do prazer ou desprazer de uma refeição aos grandes problemas planetários; da dor da morte de um amigo ao divertimento banal. Assim se tecem os dias para cada um, mas tenho o sentimento muito forte da passagem, rápida, do insignificante ao importante momento político, social; do momento egocêntrico ao momento terrocêntrico; foi isso que fiz nos diários que escrevi, e que, portanto, farei neste outro. Fazendo-os, quis dar conta, em meu caso particular e através dele, da condição humana. Montaigne dizia justamente que cada um traz consigo a condição humana. E a traz, nós acrescentaríamos, como o ponto singular de 
um holograma contendo a informação do todo do qual ele é uma minúscula parte. A condição humana está não somente nas profundezas da nossa natureza inextrincável de homo sapiens/demens, está também em nossa aptidão de padecer ou gozar segundo o acontecimento, no exercício mais ou menos não alcançado da razão, nas nossas tentativas de compreender aquilo que nos acontece e o que acontece ao mundo, está nos sucessivos estados do cotidiano, conforme o que se apresenta aos olhos, aos ouvidos, ao espírito... [...] (MORIN, 2012, p. 13-14).

Como visto, para compreender a importância dos diários e dos produtos midiáticos a partir dele originados, talvez precisemos recorrer ao conceito de mosaico do sociólogo estadunidense Howard Becker: "Cada peça acrescentada num mosaico contribui um pouco para nossa compreensão do quadro como um todo" (BECKER, 1999, p. 104). Ao considerarmos um mundo que se caracteriza pelo pensamento complexo, no sentido moriniano do termo, no qual complexus significa aquilo que é tecido em conjunto, nos parece que somente a união das múltiplas formas narrativas, biográficas ou não, poderiam propiciar uma tentativa da compreensão, em alguma medida e num dado tempo e espaço, dos fatos. Sabendo-se de antemão, também como diz Morin, que somos Homo Sapiens Sapiens Demens, e entre nossa sabidez e demência reside a única certeza da vida: a de estarmos dolorosamente cientes de nossas limitações e, na maioria dos casos, falibilidade em compreender a nós mesmos, aos outros, a natureza e o universo que nos cerca.

\section{REFERÊNCIAS}

BARDIN, Laurence. Análise de conteúdo. São Paulo, Edições 70/Almedina Brasil, 2011.

BECKER, Howard S. Métodos de Pesquisa em Ciências Sociais. 4. ed. São Paulo: Hucitec, 1999.

BENJAMIN, Walter. Sobre o conceito de história. In: BENJAMIN, Walter. Magia e técnica, arte e política. Ensaios sobre literatura e história da cultura. 7. ed. São Paulo, Brasiliense, 1994. (Obras escolhidas; v.1).

BRUM, Eliane. A vida que ninguém vê. Porto Alegre: Arquipélago Editorial, 2006. 
. Os vampiros da realidade só matam os pobres. In: Llosa, Mario Vargas et all. Dignidade! São Paulo, Leya, 2012.

O olho da rua: uma repórter em busca da literatura da vida real. São Paulo: Globo, 2008.

CITELLI, A. Comunicação e Educação. A linguagem em movimento. São Paulo: SENAC, 2000.

CRUZ, Christian Carvalho. Entretanto, foi assim que aconteceu: quando a notícia é só o começo de uma boa história. Porto Alegre: Arquipélago, 2011.

DEFOE, Daniel. A journal of the plague year. Salt Lake City: The Project Gutenberg Literary Archive Foundation, 2006.

DICKENS, Charles. American notes for general circulation. New York: Penguin Books, 2000

FARO, José Salvador. Revista Realidade, 1966-1068: tempo da reportagem na imprensa brasileira. Canoas: Ulbra/age, 1999.

FILIPOVIC, Zlata. O diário de Zlata Filipovic. São Paulo, Companhia das Letras, 1994.

FILIPOVIC, Zlata; CHALLANGER, Melanie. Vozes roubadas. São Paulo, Companhia das Letras, 2008.

FRANK, Anne. O diário de Anne Frank: o documentário mais dramático da Segunda Guerra Mundial. 12. ed. Rio de Janeiro: 1988.

GOMES, W. Transformações da Política na Era da Comunicação de Massa. São Paulo: Paulus, 2004.

GUEVARA, Ernesto Che. De moto pela América do Sul. Rio de Janeiro: Sá Editora, 2003.

JAFFE, Noemi. O que os cegos estão sonhando: com o diário de Lili Jaffe (1944-1945). São Paulo: Editora 34, 2012.

KUNSCH, Margarida M.K. Planejamento de relações públicas na comunicação integrada. São Paulo: Summus, 2003. 
LIMA, Edvaldo Pereira. Páginas ampliadas: o livro-reportagem como extensão do jornalismo e da literatura. São Paulo: Manole, 2009.

MARTINEZ, Monica. Narrativas de viagem: escritos autorais que transcendem o tempo e o espaço. Intercom - Revista Brasileira de Ciências da Comunicação. São Paulo, v. 35, n. 1, jan./jun. 2012, p. 35-52.

MITCHELL, Joseph. O Segredo de Joe Gould. São Paulo: Companhia das Letras, 2003.

MORIN, Edgard. Chorar, amar, rir, compreender. São Paulo: Edições Sesc SP, 2012.

NIJINSKY, Vaslav. The Diary of Vaslav Nijinsky. Califórnia: University California Press, 1968.

PAIVA, Fred Melo. Os infiltrados. History Channel. 2013.

PERUZZO, Cicilia M. K. Comunicação nos movimentos populares - a participação na construção da cidadania. Petr6polis, Vozes, 1998.

SILVA, M. C. C. O Infiltrado: narrativas midiáticas e uma poética antropofágica. Galáxia (PUCSP), v. 30, p. 125-137, 2015.

SOARES, I. O. Educomunicação: um campo de mediações. Comunicação \& Educação, São Paulo, n. 19, p. 12-24, set./dez. 2000.

TORTURRA, Bruno. Olho da rua. Piauí. Rio de Janeiro, nº 87, dez 2013, p. 23-31.

VASSILTCHIKOV, Marie. Diários de Berlim: 1940-1945. São Paulo: Boitempo, 2015.

- Quinta-feira, 20 de julho. Pelos olhos de Missie: a princesa russa que viu e narrou o Reich. Folha de S.Paulo, 15 fev. 2015, p. C8-9.

VERÔNICA; NINA; ANA. "Cenas de um casamento". Piauí. Rio de Janeiro, n. 115 , ou. 2015, p. 30-37.

WOLFE, Virginia. Diário de Virginia Woolf. São Paulo: Companhia das Letras, 1989, p. 132. 
AÇÃO MIDIÁTICA, n.11. Jan/jun. 2016. Curitiba. PPGCOM-UFPR. ISSN 2238-0701

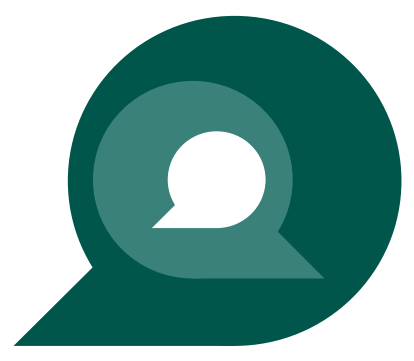

